\title{
Fractional Carbon Dioxide Laser Resurfacing
}

\author{
William M. Ramsdell, M.D. ${ }^{1}$ \\ ${ }^{1}$ Private practice, Austin, Texas \\ Semin Plast Surg 2012;26:125-130.
}

\begin{abstract}
Address for correspondence and reprint requests William M. Ramsdell, M.D., 102 Westlake Drive, Suite 100, Austin Texas, 78746

(e-mail:wmr@centexderm.com).
\end{abstract}
Abstract
Keywords
- fractional
- ablative
- collagen
$-\mathrm{CO}_{2}$

Currently available ablative fractional $\mathrm{CO}_{2}$ lasers provide excellent results and diminish down time with fewer complications than previous generation $\mathrm{CO}_{2}$ lasers. Mechanisms of action, treatment parameters, as well as pre- and postoperative care will be discussed.
The sophisticated lasers used today might seem unimaginable to Dr. Leon Goldman who first studied laser-cutaneous interactions in the 1960s. ${ }^{1}$ In 1983, Anderson and Parrish fundamentally changed our usage of lasers with the groundbreaking concept of photothermolysis via pulsed radiation. ${ }^{2}$ During the 1990s, the ability to apply high energy with shortpulse durations made what is now termed "traditional" $\mathrm{CO}_{2}$ very popular. Never before had a device been able to produce such changes in the appearance and function of skin. Many physicians consider the fully ablative traditional $\mathrm{CO}_{2}$ laser to be the gold standard. Certainly, no other device can achieve the same results. Those results, however, come with side effects such as prolonged erythema and delayed hypopigmentation for some patients. Dr. Jeffrey Dover believes that today there are few instances where traditionally ablative $\mathrm{CO}_{2}$ laser resurfacing is indicated (Personal Communication, January 16, 2012).

In 2004, Manstein et al developed a technique of creating thermal injury to skin in a fractional pattern in an attempt to achieve results similar to fully ablative resurfacing while maintaining an acceptable side-effect profile. ${ }^{3}$ Following initial development of nonablative fractional lasers, ablative fractional $\mathrm{CO}_{2}$ lasers entered the market in hopes of delivering even better results.

\section{Mechanisms of Actions}

The benefits of $\mathrm{CO}_{2}$ laser resurfacing are undeniable, whether fully ablative or fractional. The mechanisms by which such improvement is achieved have been the subject of much debate. ${ }^{4}$ Although fully ablative traditional and fractional $\mathrm{CO}_{2}$ lasers have distinctive characteristics, much of the re- search on fully ablative $\mathrm{CO}_{2}$ resurfacing is applicable to fractional resurfacing. ${ }^{5}$ All $\mathrm{CO}_{2}$ lasers have a wavelength of $10,600 \mathrm{~nm}$, heavily absorbed by water. To achieve ablation without excessive thermal damage, a fluence of $5 \mathrm{~J} / \mathrm{cm}^{2}$ must be delivered within a pulse duration of $<1 \mathrm{~ms}$, the generally agreed upon thermal relaxation time of skin.

The denaturation temperature of collagen is conventionally stated to be $66.8^{\circ} \mathrm{C}$, although this varies. ${ }^{4}$ Once denatured by laser-generated heat, collagen rapidly contracts as fibers shrink to one-third of their length. ${ }^{6}$ The shrinkage of collagen is the primary mechanism of skin tightening, although vaporization of intracellular water and ablation contribute as well. Next, a wound-healing phase is initiated characterized by extremely high levels of collagenases (matrix metalloproteinases), which degrade the fragmented collagenous matrix. ${ }^{7}$ Rapid reconstitution of the epidermis from adjacent epidermal cells contrasts with healing after traditional resurfacing in which new epidermis is derived from cells that migrate from adnexal structures. A prolonged period of dermal neocollagenesis of up to at least 6 months follows. ${ }^{8}$

Although tissue ablation certainly plays a role in effectiveness, the depth of deep rhytides exceeds the depth of ablation. ${ }^{9,10}$ Residual thermal damage represents the true depth of injury and the primary factor leading to effectiveness. ${ }^{4}$ Residual thermal damage is increased with higher fluence, ${ }^{11,12}$ whereas increased density results in greater depth of ablation.

\section{Patient Selection}

As with any cosmetic procedure, patient selection is important. Realistic expectations and a thorough understanding of
Issue Theme Cosmetic Laser Resurfacing; Guest Editor, Ramsey Markus, M.D.
Copyright @ 2012 by Thieme Medical Publishers, Inc., 333 Seventh Avenue, New York, NY 10001, USA. Tel: +1(212) 584-4662.
DOI http://dx.doi.org/ 10.1055/s-0032-1329414. ISSN 1535-2188. 
the procedure and especially postoperative care are crucial. Although most patients require only one treatment, patients should be prepared for the possibility that more than one treatment may be necessary for best results. Contraindications to treatment include active cutaneous infection, diseases that inhibit healing, such as scleroderma, and a history of any diseases that Koebnerize such as vitiligo and psoriasis. Recent isotretinoin therapy or a history of radiation at the treatment site demands caution and nonaggressive parameters.

\section{Preoperative Care}

Regardless of history, all patients receive preoperative antiviral prophylaxis with valacyclovir $500 \mathrm{mg}$ twice daily beginning one day preoperatively and continued for 10 days. Most laser surgeons also prescribe an antibiotic such as cefadroxil, dicloxacillin, doxycycline, or ciprofloxacin during the same period. ${ }^{13}$ Others believe that antibiotics for Gram+ organisms only promote Gram infection. Fluconazole $200 \mathrm{mg}$ is given on the day of surgery. Prophylactic facial cleansing with chlorhexidine twice daily for 3 days preoperatively may further decrease the incidence of postoperative infection. Some surgeons prescribe intranasal mupirocin preoperatively. Preconditioning the skin with tretinoin in an attempt to speed healing and reduce the incidence of postoperative milia and acne is of questionable benefit and promotes increased postoperative erythema. ${ }^{14-18}$

\section{Treatment}

Fractional resurfacing begins with appropriate laser precautions and sedation of choice. Although general or tumescent anesthesia may be used, the liberal application of topical anesthesia 1 to 2 hours before surgery is usually adequate. Kilmer believes that a hydrophilic topical anesthetic such as EMLA (eutectic mixture of lidocaine and prilocaine; AstraZeneca Pharmaceuticals, LP, London, UK) may alter the response to the laser ensuring fewer side effects. ${ }^{19}$ Because the primary target of $\mathrm{CO}_{2}$ lasers is water, this makes intuitive sense. However, Naouri et al believe the water content of topical anesthetics irrelevant. ${ }^{20}$ Certainly, topical anesthesia should have very little effect on a narrow, deep ablative beam. Whether more superficial resurfacing is affected by topical anesthesia is open to debate. In addition to topical anesthesia, forced cold air provided by a Zimmer Cooler (LaserMed, Monroe, CT) or similar device is helpful.

Currently, there are several excellent fractional $\mathrm{CO}_{2}$ devices on the market. ${ }^{21}$ This discussion will be limited to the specifics of using the Lumenis Ultrapulse Encore fractional $\mathrm{CO}_{2}$ laser for photoaging and scarring of the face and neck. Two delivery devices offer dual depth ablation, Active FX and Deep FX, via separate handpieces. The Active FX handpiece has a collimated 1.3-mm spot size delivered in a nonsequential array (Cool Scan mode) to minimize thermal damage. Available energy varies from $2 \mathrm{~mJ}\left(150 \mathrm{~mJ} / \mathrm{cm}^{2}\right)$ to $225 \mathrm{~mJ}\left(169 \mathrm{~J} / \mathrm{cm}^{2}\right)$. Power settings range from $1 \mathrm{~W}(4.4 \mathrm{~Hz})$ to $60 \mathrm{~W}(600 \mathrm{~Hz})$. A computer pattern generator delivers seven patterns in nine different size options and nine density options. It is the ability to alter the density that distinguishes fractional lasers from traditionally fully ablative ones. For density settings, 1 to 3 with the square pattern, density varies between $55 \%$ and $82 \%$. Densities 4 to 9 are fully ablative (100\%) although the depth is much less than with traditional $\mathrm{CO}_{2}$ lasers.

Active FX creates a shallow, broad ablative crater that can extend into superficial papillary dermis. One or two passes are commonly used. Typical energy settings for facial skin range from 100 to $125 \mathrm{~mJ}$. Density settings from 2 to 4 are typical, but may be increased for difficult cases such as acne scarring. Periorbital skin treatment parameters range from 60 to $90 \mathrm{~mJ}$, density 2 to 3 . Treatment of neck, chest, and extremities is possible at reduced settings such as 70 to $80 \mathrm{~mJ}$, density 1 to 2 . Opinion varies regarding whether to debride between laser passes for traditional resurfacing. ${ }^{22-25}$ For fractional resurfacing, it is not necessary.

For deep rhytides, scarring and for maximum collagen regeneration, Deep FX is used initially or exclusively. The Deep FX handpiece produces a narrower, noncollimated beam at $0.12 \mathrm{~mm}$ with four pattern and six size options. One pulse or 2-stacked pulses can be used. Power ranges up to $600 \mathrm{~Hz}$ with a single pulse and to $300 \mathrm{~Hz}$ with double pulsing. Energy settings between $2.5 \mathrm{~mJ}$ and $50 \mathrm{~mJ}$ are available. At $2.5 \mathrm{~mJ}$, the ablation depth is quite shallow, $76 \mu \mathrm{m}$, which extends through the epidermis and possibly to superficial papillary dermis depending on site. Although the depth can be increased to $1600 \mu$ or more, these settings are much too powerful to be clinically appropriate.

A Deep FX energy setting between 15 to $22.5 \mathrm{~mJ}$ is typical for the face. At $22.5 \mathrm{~mJ}$, ablation extends to $\sim 675 \mu \mathrm{m}$, which correlates with deep dermis (depending on skin thickness). This depth will encompass most cases of solar elastosis. Density settings of 5 to $25 \%$ are available. This translates for a square scan area of $10 \times 10 \mathrm{~mm}$, from 196 spots at density $5 \%$ to 841 spots at $25 \%$. Deep FX at aggressive settings can punch all of the way through eyelid skin. Safe settings for skin within the bony orbit include settings from 8 to $10 \mathrm{~mJ}$ and density 5 to $15 \%$. Settings of 8 to $10 \mathrm{~mJ}$, density 5 to $15 \%$ are appropriate for off of the face sites such as neck, chest, and extremities. The author uses one pulse only for all applications except scarring, for which double pulsing is sometimes used.

Oni et al documented that, on facial skin, a single pulse at $15 \mathrm{~mJ}$ extended to an average $416 \mu \mathrm{m}$, which correlates with mid-dermis. ${ }^{26}$ Interestingly, double pulsing at $15 \mathrm{~mJ}$ was histologically equivalent to a single pulse at $30 \mathrm{~mJ}$, extending $881 \mu \mathrm{m}$ and $854 \mu \mathrm{m}$, respectively (deep reticular dermis). The relevance of this in terms of clinical outcome has yet to be determined. Little data exists in the peer-reviewed literature regarding how best to combine Active FX with Deep FX.

Because the precise boundaries of the scanned imprints on the skin can be difficult to see, skip areas, or worse, pulse stacking can occur with Deep FX resurfacing. Because treated skin will turn red or urticate several minutes after treatment, untreated areas can be recognized and treated. If Active FX treatment is planned following Deep FX, areas missed with Deep FX will usually blend in. 
A
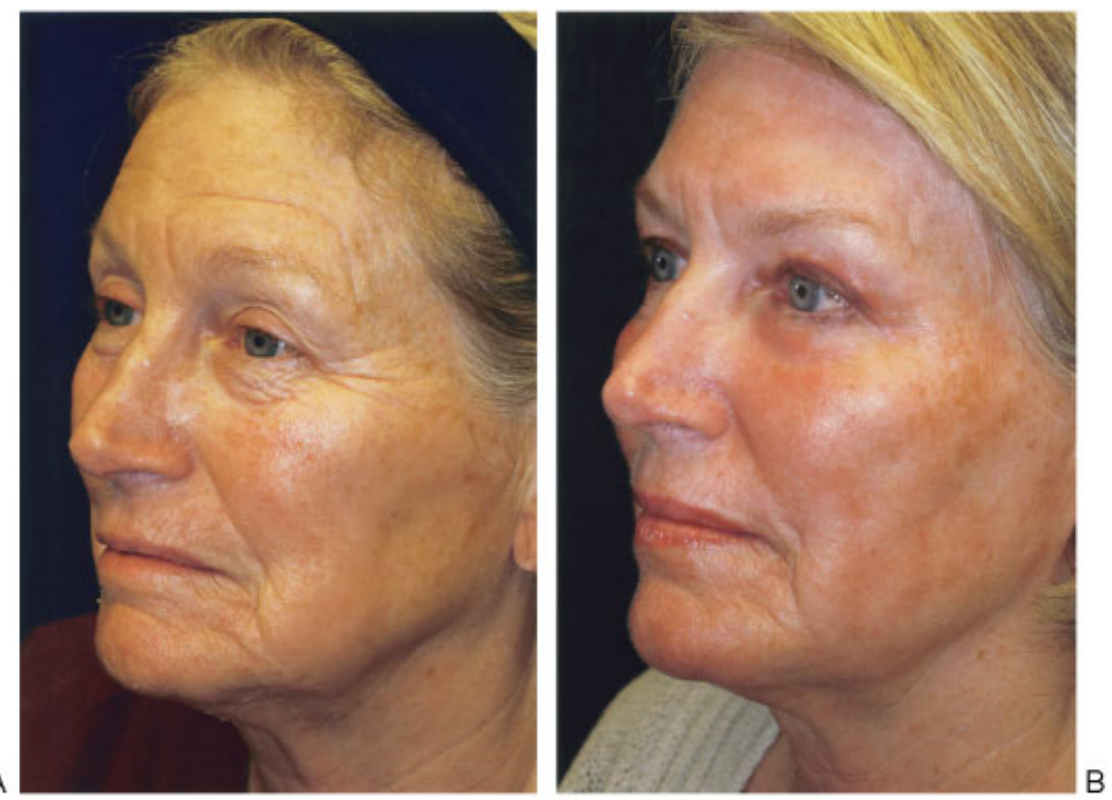

Figure 1 A 66-year-old woman (A) Before and (B) after Active FX resurfacing and transconjunctival lower blepharoplasty. Active FX settings: two passes, $100 \mathrm{~mJ}, 60 \mathrm{~W}$, pattern 1, size 9, density 6; periorbital areas: two passes, $80 \mathrm{~mJ}, 45 \mathrm{~W}$, pattern 5, size 6 , density 4 and density 3; feathering with handpiece held tangentially: $80 \mathrm{~mJ}, 45 \mathrm{~W}$, pattern 1, size 9, density 3.

\section{Postoperative Care}

Meticulous postoperative care is absolutely crucial to avoid infection and scarring. Cold soaks of white vinegar 1 tsp to 1 cup water or aluminum acetate (Domeboro, Bayer HealthCare, Morristown, NJ) soaks reduce erythema, edema, and provide antisepsis. The skin should be kept moist with white petrolatum or Aquaphor ${ }^{\circledR}$ (Beiersdorf, Wilton, CT). Other topicals are strongly discouraged. The concept of promoting rapid healing via use of autologous platelet-rich plasma has recently been introduced. ${ }^{27}$
Occlusive dressings such as Silon II (BioMed Sciences, Inc, Allentown, PA) have been shown to speed healing, reduce inflammation, and possibly improve results following traditional resurfacing. ${ }^{4,28,29}$ The dressings are cumbersome and not necessary for most fractional resurfacing. The author still uses Silon II with aggressive treatments for severe acne scarring. Reepithelialization usually takes 3 to 6 days. At that point, a light moisturizer and sunscreen may be used. Mild to moderate erythema persists for several weeks. Topical vitamin $C$ can be used to encourage neocollagenesis and reduce erythema. ${ }^{30,31}$
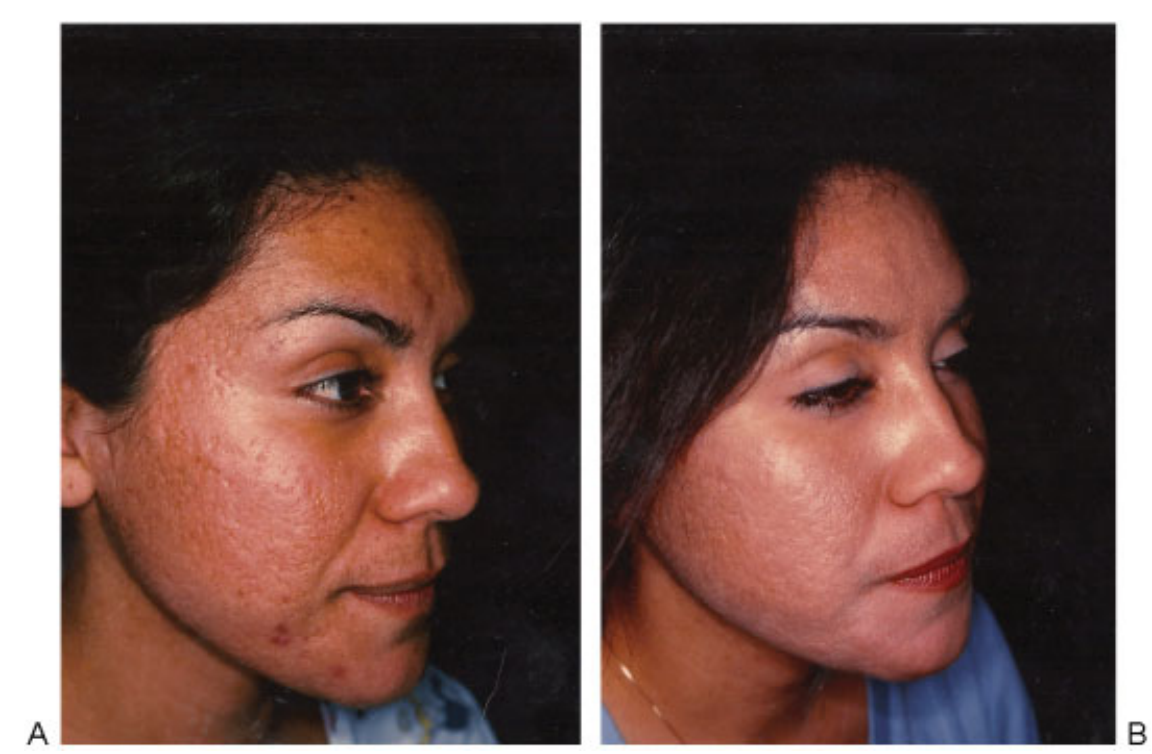

Figure 2 Combination ice-pick and box-car-type scarring. (A) Before and (B) after punch excisions followed by two passes of Active FX at $125 \mathrm{~mJ}$, density 6. Periorbital areas: one pass Active FX at $80 \mathrm{~mJ}$, density 3. 
A
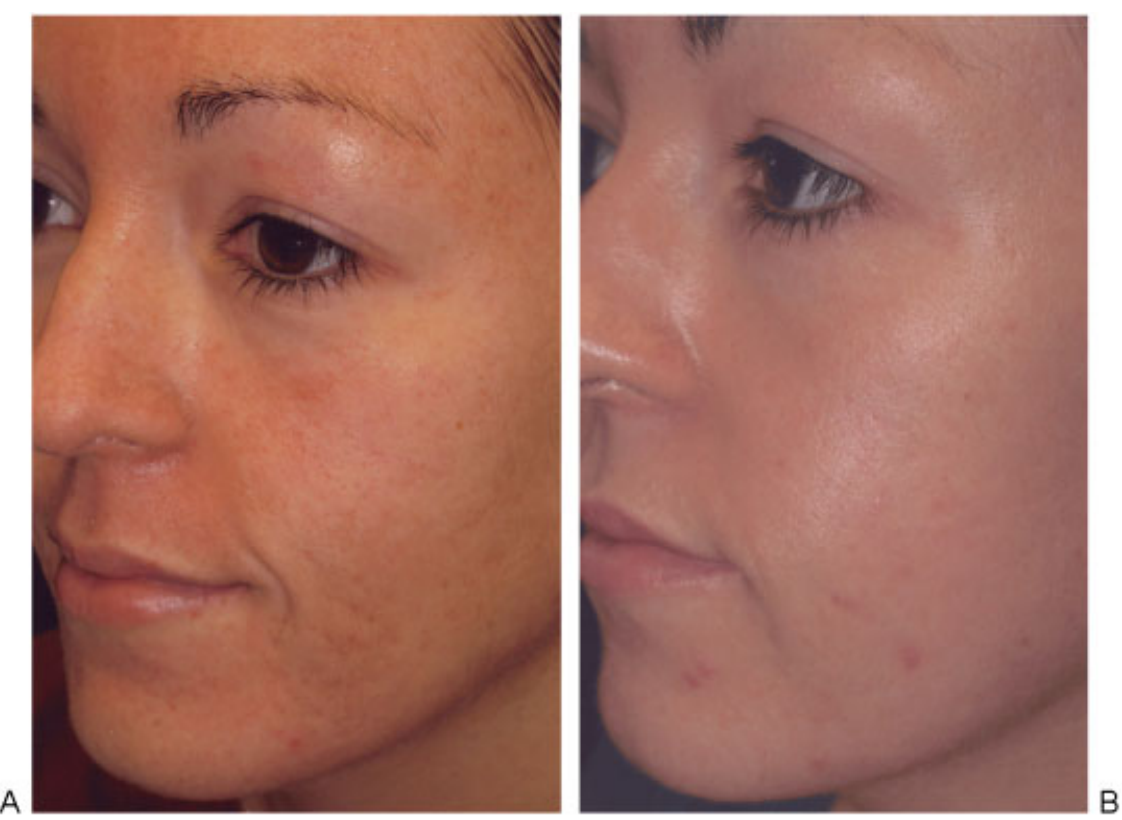

Figure 3 Box-car-type acne scarring. (A) Before and (B) after fractional resurfacing. One pass of Deep FX at 22.5 mJ, $10 \%$ density, one pulse, followed by Active FX at $125 \mathrm{~mJ}$, density 5. Periorbital areas: one pass Active FX at $80 \mathrm{~mJ}$, density 2.

\section{Efficacy}

Efficacy can be difficult to assess because histologic changes do not always correlate with changes in appearance. Moreover, changes in appearance are difficult to quantify and subjective for both patient and physician. Virtually all patients show at least modest improvement (-Fig. 1). In general, thin skin responds better than thick. Young skin is capable of producing more collagen than old skin. Rahman found moderate or better improvement in $83 \%$ of patients. ${ }^{32}$ Ortiz documented 50 to $75 \%$ improvement at 3 months with 25 to $50 \%$ improvement long term. ${ }^{33}$ Improvement of eyelid rhytides by $53 \%$ has been documented as well. ${ }^{34}$

Acne scarring is more difficult to treat and realistic expectations should be stressed during the consultation. After 2 to 3 treatments for acne scarring, 26 to 50\% improvement in texture and atrophy has been noted. ${ }^{35}$ The same study documented $68 \%$ improvement in the depth of scars as measured by
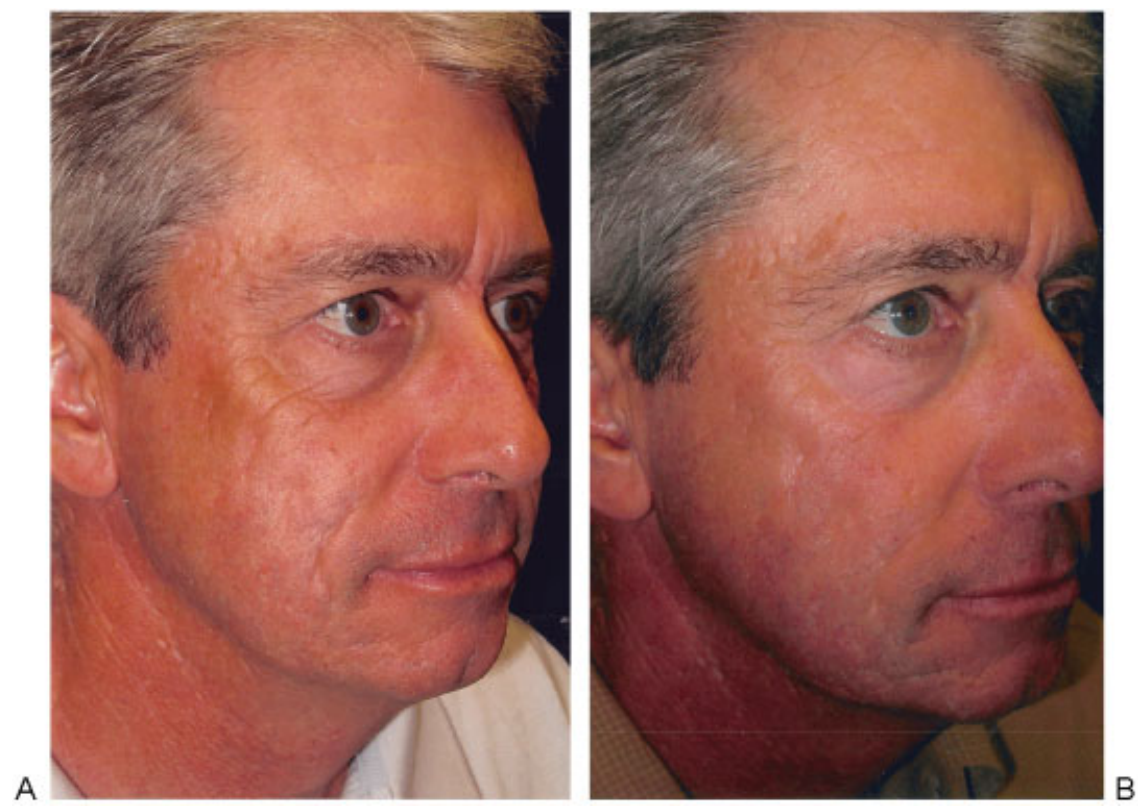

Figure 4 Rolling scars. (A) Before and (B) after treatment, showing only modest improvement despite aggressive settings. Punch excisions were followed by both Deep FX and Active FX. Deep FX: 125 mJ, density 20\%, two pulses to most severely affected areas. Active FX: 1 pass at $125 \mathrm{~m}$ J, density 7 to entire face except periorbital areas: $80 \mathrm{~m}$ J, density 4 . Silon II was placed as a wound dressing for 3 days to speed healing and reduce inflammation. 


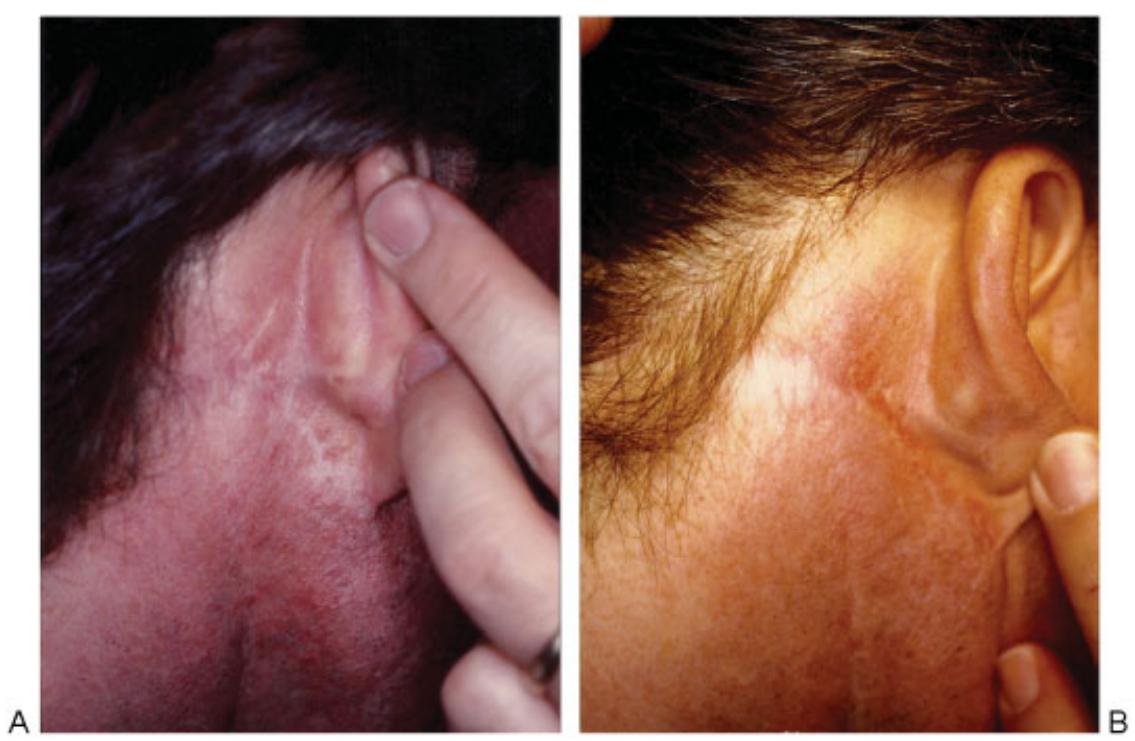

Figure 5 Facelift scar. (A) Before and (B) after fractional resurfacing. Two passes of Active FX at 90 mJ, density 4.

the Primos three-dimensional optical system. Ice pick-type scars should undergo punch excisions prior to laser therapy (-Fig. 2). Boxcar-type scarring responds well (-Fig. 3). Most challenging to treat are rolling scars ( - Fig. 4 ). These patients may benefit from a facelift superior to the superficial muscular aponeurotic system (SMAS) first. This stretches the skin, thereby effacing some of the rolling depressions. The increased tension placed on fibroblasts may enhance subsequent collagen formation. ${ }^{7}$ Laser settings for rolling scars should be aggressive and many patients will require more than one treatment. Regardless of the etiology of scarring, thin scars respond better than thick ones (-Fig. 5).

\section{Conclusion}

Fractional $\mathrm{CO}_{2}$ resurfacing represents one of the most useful devices produced by 50 years of research into laser-cutaneous interactions. Patients can expect excellent results with few complications. Additional research will further improve our ability to provide the best of care for our patients.

\section{References}

1 Goldman L, Wilson RG, Hornby PM, Meyer RG. Radiation from a Q-switched ruby laser. Effect of repeated impacts of power output of 10 megawatts on a tattoo of a man. J Invest Dermatol 1965;44: 69-71

2 Anderson RR, Parrish JA. Selective photothermolysis: precise microsurgery by selective absorption of pulsed radiation. Science 1983;220(4596):524-527

3 Manstein D, Herron GS, Sink RK, Tanner H, Anderson RR. Fractional photothermolysis: a new concept for cutaneous remodeling using microscopic patterns of thermal injury. Lasers Surg Med 2004; 34(5):426-438

4 Ross EV, McKinlay JR, Anderson RR. Why does carbon dioxide resurfacing work? A review. Arch Dermatol 1999;135(4): $444-454$
5 Reilly MJ, Cohen M, Hokugo A, Keller GS. Molecular effects of fractional carbon dioxide laser resurfacing on photodamaged human skin. Arch Facial Plast Surg 2010;12(5):321-325

6 Gardner ES, Reinisch L, Stricklin GP, Ellis DL. In vitro changes in non-facial human skin following $\mathrm{CO} 2$ laser resurfacing: a comparison study. Lasers Surg Med 1996;19(4):379-387

7 Fisher GJ, Varani J, Voorhees JJ. Looking older: fibroblast collapse and therapeutic implications. Arch Dermatol 2008; 144(5):666-672

8 Orringer JS, Kang S, Johnson TM, et al. Connective tissue remodeling induced by carbon dioxide laser resurfacing of photodamaged human skin. Arch Dermatol 2004;140(11):1326-1332

9 Fitzpatrick R, Smith S, Sriprachya-anunt S. Depth of vaporization with the UltraPulse CO2 laser. Proc SPIE 1997;2970:392-394

10 Ross EV, Grossman MC, Duke D, Grevelink JM. Long-term results after CO2 laser skin resurfacing: a comparison of scanned and pulsed systems. J Am Acad Dermatol 1997;37(5 Pt 1):709-718

11 Bernstein EF, Brown DB, Kenkel J, Burns AJ. Residual thermal damage resulting from pulsed and scanned resurfacing lasers. Dermatol Surg 1999;25(10):739-744

12 Saluja R, Khoury J, Detwiler SP, Goldman MP. Histologic and clinical response to varying density settings with a fractionally scanned carbon dioxide laser. J Drugs Dermatol 2009;8(1):17-20

13 Ross EV, Amesbury EC, Barile A, Proctor-Shipman L, Feldman BD. Incidence of postoperative infection or positive culture after facial laser resurfacing: a pilot study, a case report, and a proposal for a rational approach to antibiotic prophylaxis. J Am Acad Dermatol 1998;39(6):975-981

14 Lowe NE, Lask G, Griffin ME. Laser skin resurfacing. Pre and post treatment guidelines. Dermatol Surg 1995;21:1017-1019

15 Goldman MP. Pre- and postoperative care of the laser patient. Int J Aesthetic Restorative Surg 1997;5:46-49

16 Gilchrest BA. Treatment of photodamage with topical tretinoin: an overview. J Am Acad Dermatol 1997;36(3 Pt 2):S27-S36

17 Hung VC, Lee JY, Zitelli JA, Hebda PA. Topical tretinoin and epithelial wound healing. Arch Dermatol 1989;125(1):65-69

18 Nyirady J, Grossman RM. Use of tretinoin in precosmetic and postcosmetic procedures. A review. Cos Dermatol 2003;16(5): 39-47

19 Kilmer SL, Chotzen VA, Silva SK, McClaren ML. Safe and effective carbon dioxide laser skin resurfacing of the neck. Lasers Surg Med 2006;38(7):653-657 
20 Naouri M, Atlan M, Perrodeau E, et al. High-resolution ultrasound imaging to demonstrate and predict efficacy of carbon dioxide fractional resurfacing laser treatment. Dermatol Surg 2011; 37(5):596-603

21 Waibel J, Beer K, Narurkar V, Alster T. Preliminary observations on fractional ablative resurfacing devices: clinical impressions. J Drugs Dermatol 2009;8(5):481-485

22 Ross EV, Mowlavi A, Barnette D, Glatter RD, Grevelink JM. The effect of wiping on skin resurfacing in a pig model using a high energy pulsed CO2 laser system. Dermatol Surg 1999;25(2): 81-88

23 David L, Ruiz-Esparza J. Fast healing after laser skin resurfacing. The minimal mechanical trauma technique. Dermatol Surg 1997;23(5):359-361

24 Ruiz-Esparza J, Barba Gomez JM, Gomez de la Torre OL, et al Erythema after laser skin resurfacing. Dermatol Surg 1998;24: 31-34

25 Niamtu J III. To debride or not to debride? That is the question: rethinking char removal in ablative $\mathrm{CO} 2$ laser skin resurfacing. Dermatol Surg 2008;34(9):1200-1211

26 Oni G, Robbins D, Bailey S, Brown SA, Kenkel JM. An in vivo histopathological comparison of single and double pulsed modes of a fractionated CO(2) laser. Lasers Surg Med 2012;44(1):4-10

$27 \mathrm{Na}$ JI, Choi JW, Choi HR, et al. Rapid healing and reduced erythema after ablative fractional carbon dioxide laser resurfacing combined with the application of autologous platelet-rich plasma. Dermatol Surg 2011;37(4):463-468

28 Batra RS, Ort RJ, Jacob C, Hobbs L, Arndt KA, Dover JS. Evaluation of a silicone occlusive dressing after laser skin resurfacing. Arch Dermatol 2001;137(10):1317-1321

29 Goldman MP, Roberts TL III, Skover G, Lettieri JT, Fitzpatrick RE. Optimizing wound healing in the face after laser abrasion. J Am Acad Dermatol 2002;46(3):399-407

30 Alster TS, West TB. Effect of topical vitamin C on postoperative carbon dioxide laser resurfacing erythema. Dermatol Surg 1998;24(3):331-334

31 Pinnel SR, Murad S, Darr D. Induction of collagen synthesis by ascorbic acid. A possible mechanism. Arch Dermatol 1987; 123(12):1684-1686

32 Rahman Z, MacFalls H, Jiang K, et al. Fractional deep dermal ablation induces tissue tightening. Lasers Surg Med 2009;41 (2):78-86

33 Ortiz AE, Tremaine AM, Zachary CB. Long-term efficacy of a fractional resurfacing device. Lasers Surg Med 2010;42(2): 168-170

34 Kotlus BS. Dual-depth fractional carbon dioxide laser resurfacing for periocular rhytidosis. Dermatol Surg 2010;36(5):623-628

35 Chapas AM, Brightman L, Sukal S, et al. Successful treatment of acneiform scarring with $\mathrm{CO} 2$ ablative fractional resurfacing. Lasers Surg Med 2008;40(6):381-386 